BULLETIN Bulletin hispanique

HISPANIQUE Université Michel de Montaigne Bordeaux

120-1 | 2018

Varia

\title{
Dámaso Alonso escribe a Luis Rosales
}

Edición y análisis de doce cartas

Dámaso Alonso écrit à Luis Rosales. Édition et analyse de douze lettres

Dámaso Alonso writes to Luis Rosales. The edition and analysis of twelve letters

Dolores Pons Rodríguez

\section{(2) OpenEdition}

Journals

Edición electrónica

URL: https://journals.openedition.org/bulletinhispanique/6028

DOI: 10.4000/bulletinhispanique.6028

ISSN: 1775-3821

Editor

Presses universitaires de Bordeaux

Edición impresa

Fecha de publicación: 30 junio 2018

Paginación: 271-290

ISBN: 979-10-300-0298-0

ISSN: 0007-4640

Referencia electrónica

Dolores Pons Rodríguez, «Dámaso Alonso escribe a Luis Rosales», Bulletin hispanique [En línea], 120-1 | 2018, Publicado el 01 enero 2022, consultado el 08 enero 2022. URL: http://journals.openedition.org/ bulletinhispanique/6028; DOI: https://doi.org/10.4000/bulletinhispanique.6028 


\title{
Dámaso Alonso escribe a Luis Rosales. Edición y análisis de doce cartas
}

\author{
Dolores Pons RodríGuez \\ Universidad de Sevilla
}

L'article propose l'édition et l'étude contextualisée des lettres que Dámaso Alonso a adressées à Luis Rosales. Ces lettres sont conservées à l'Archivo Histórico Nacional. Il s'agit de douze textes dans lesquels Dámaso Alonso traite de questions éditoriales, personnelles, littéraires.

Mots-clés : Dámaso Alonso, Luis Rosales, philologie, exil, lettres.

En este trabajo se editan y estudian en su contexto las cartas de Dámaso Alonso dirigidas a Luis Rosales que se conservan en el Archivo Histórico Nacional (Madrid). Se trata de doce escritos en que Alonso se dirige al poeta Rosales para tratar asuntos editoriales, personales o de naturaleza literaria.

Palabras clave: Dámaso Alonso, Luis Rosales, filología española, exilio, epistolario.

This article offers the edition and contextualized study of the letters Dámaso Alonso wrote to Luis Rosales. These letters are kept at the Archivo Histórico Nacional: twelve texts in which Dámaso Alonso is dealing with publishing, personal, literary matters.

Keywords: Dámaso Alonso, Luis Rosales, Spanish Philology, Exile, Letters.

\footnotetext{
* Este trabajo es uno de los frutos del proyecto FFI2013-45222-P «La escritura historiográfica en espańol» financiado por el Ministerio de Economía y Competitividad del Gobierno español. Agradezco a Luis Rosales Fouz su gentileza y generosidad al leer este trabajo en su versión preliminar y ayudarme con algunos datos.
} 
1. Abre Dámaso Alonso su trabajo «España en las cartas de Pedro Salinas» con unas palabras que apuntan directamente a la clase de legitimidad que tiene la edición de un fondo epistolar ajeno. Publicando fragmentos de las cartas que Salinas le escribió desde el exilio, afirma: «Las cartas de un escritor (y en general todas las cartas) pertenecen a quien las escribió; de ningún modo a quien las recibe. Es un principio que señalan las leyes o la jurisprudencia, y que además está exigido aún por la delicadeza menos delicada» (Alonso 1962 b: 154).

Los materiales de archivo y biblioteca de Luis Rosales fueron legados años después de su muerte a la Junta de Andalucía (sita en Granada, allí se guardan sus libros) y al Archivo Histórico Nacional (en Madrid, donde se custodian sus papeles y anotaciones literarias y personales). A la muerte de Dámaso Alonso, su impresionante archivo fue también reubicado en otra institución, la Real Academia Española. Es historia que se repite para muchos de los integrantes de la generación de profesores, poetas y poetas-profesores que vivieron en la España del siglo XX. Fueron poseedores de ingentes archivos que interesan no solo por lo que contienen sobre la obra propia, sino también por cuanto guardan de referencias, cartas y documentación ajena. La ubicación póstuma de sus legados nos informa de qué avatares de tipo personal vivieron: el fondo de Amado Alonso se custodia fundamentalmente en la biblioteca de Harvard, sede final de su exilio, lo que contrasta con la escasez de documentos de su pertenencia que se guardan en su pueblo natal de Lerín (Navarra) que con voluntarismo le rinde homenaje desde 2001 en forma de fundación. En cambio, están en la rae los legados de Rodríguez-Moñino y María Brey; en Madrid, la fundación Xavier Zubiri alberga parte de los papeles de Américo Castro, donados por su hija Carmen Castro, viuda de Zubiri; la Biblioteca Valenciana, por su parte, alberga desde 2002 gran parte de las posesiones librescas y documentales de Rafael Lapesa ${ }^{1}$.

Convenientemente catalogados y en consulta en general abierta a los investigadores, el trabajo con esta clase de fondos nos plantea interrogantes que no nos presenta la edición de cualquier documento cuyo poseedor primero desconocemos o queda lejos en el tiempo. Digitalizadas y consultables por cualquier interesado, están en el Fondo Luis Rosales del Archivo Histórico Nacional cartas, telegramas y postales que le remitieron personas de su tiempo, muchas de las cuales aún están vivas. Leer sus inquietudes íntimas o laborales y transmitirlas en el franco camino que abre la consulta digital nos hace repensar la frase de don Dámaso de las cartas pertenecen a quien las escribió.

1. Del amplio epistolario de Dámaso Alonso tenemos una parte editada, en forma de libros (como el de Ruiz Gálvez, que recoge la correspondencia con Bataillon) o artículos científicos (Hernández 1993; Polo 2007; Polo 2011). Más cartas autógrafas de Dámaso Alonso, que permanecen inéditas, se guardan en el Legado Rodríguez-Mońino de la rae; otras pueden verse en los archivos digitales de la Fundación Francisco Umbral o en el Repositorio Documental de la Universidad de Salamanca (dentro del archivo personal de Ricardo Espinosa Maeso). Fondos como el de Pedro Sainz Rodríguez, en la Fundación Universitaria Española, albergan también cartas de interés. 
En las páginas que siguen nos lanzamos a la edición de una docena de escritos dirigidos a Luis Rosales por considerarlos representativos e informativos de las relaciones intelectuales y sociales de la Filología del medio siglo. Ofrecemos, pues, la transcripción e interpretación contextualizada de un conjunto de escritos remitidos por Dámaso Alonso (Madrid, 22-X-1898 / Madrid, 25-I1990) a Luis Rosales Camacho (Granada, 31-V-1910/ Madrid, 14-X-1992) y conservados hoy en el Archivo Histórico Nacional. En conjunto, se trata de cartas y notas de corta o mediana extensión, que abordan cuestiones de índole privada y algunas otras relativas a lances y avisos sobre temas de su investigación. Unas y otras reflejan la personalidad del maestro y los efectos del medio en que se desenvolvió su trabajo. Cabe recordar en este punto un escrito menor de Dámaso Alonso (1962 a: 75) donde transcribe sendas cortas epístolas del siglo Xvir, de tipo cotidiano, conservadas al dorso de unos comentarios gongorinos. Al presentarlas decía don Dámaso que estas eran «pobres cartas perdidas [...] la lenta carta de la dicha, la súbita de la desgracia. A veces la casualidad nos ha conservado una de esas cartas sin importancia. $\mathrm{Y}$ en ellas se nos abre una vislumbre fría hacia los soles de aquellos minutos remotos». Si se elige este conjunto epistolar para este trabajo es porque, si bien estas pudieron ser también en su momento, como las que Dámaso editó, cartas sin importancia, a los ojos del lector actual pueden servir como testimonio de la vividura profesional y personal de la España de la segunda mitad del siglo $\mathrm{Xx}$ vista a través de la relación amistosa entre dos intelectuales como Rosales y Alonso. Otras figuras de su tiempo, con cargos políticos o docentes en la España franquista o en el exilio, o con relevancia en el mundo artístico o editorial de su tiempo, se hacen presentes también en esta corta colección de textos.

2. El contacto entre Rosales y Alonso es previo a la Guerra Civil, aunque estas cartas son posteriores a tan trágico acontecimiento. Rosales se había trasladado desde Granada a Madrid en 1931 para terminar sus estudios universitarios de Letras y en 1933 ya empezaron a aparecer poemas suyos en revistas como Los cuatro vientos, dirigida por Guillén y Salinas. Nuestros dos autores debieron de conocerse en el círculo intelectual y poético de la preguerra y en ese tiempo iniciaron su amistad. Esta se refleja en colaboraciones, dedicatorias y estudios monográficos. La tesis doctoral de Rosales (presentada en 1950) fue dirigida por Dámaso, y este lo cita en artículos de investigación donde además de la referencia libresca o de la discusión erudita ${ }^{2}$ hay alguna nota calificativa al amigo. Alonso dedicó de forma monográfica varios escritos a Rosales (Alonso 1944 [1962]; Alonso 1964 [1975]), lo menciona como investigador y analista textual $^{3}$, lo incluye en el grupo de los poetas desarraigados con Leopoldo Panero y

2. En el primer escrito de conexión entre ambos, la reseña que hace Dámaso Alonso al segundo volumen de la colección antologada de Rosales y Vivanco Poesía heroica del Imperio se observa ya que la conexión personal y científica no anuló la discrepancia intelectual. Por ejemplo, en dicha reseńa, Alonso disiente de Rosales en el sentido original o continuista de la lírica barroca (Rivero Machina 2013: n. 17).

3. Lo vemos, por ejemplo, en el ensayo de Alonso «Función imaginativa del lenguaje» donde 
Luis Felipe Vivanco y prologa la edición en Espasa Calpe (1979) de un volumen que recoge sus Rimas y La casa encendida. Por su parte, Rosales también hace patente en su obra la huella de su amistad con Dámaso Alonso, de quien se sentía discípulo directo ${ }^{4}$. A él le dedica "Aprendiendo a ser mano", que es, a decir de la última editora de Rosales, Noemí Montetes-Mairal (2010: 148) "uno de los poemas más cruciales de Rimas», con la dedicatoria: "A Dámaso Alonso, a quien debo tan continuado magisterio en la amistad y en el trabajo", y hay una «Rima final» de Rosales en el Homenaje universitario a Dámaso Alonso. Reunido por los estudiantes de Filología románica, curso 1968-1969 (Madrid: Universidad de Madrid, 1970). Son estos escritos diálogos intelectuales que se establecen entre las publicaciones científicas y poéticas de ambos autores. Por otro lado, ese diálogo también dio lugar a colaboraciones: juntos, y con la esposa de Alonso5, firmaron la antología Primavera y flor de la literatura hispánica (cfr. Alonso / Galvarriato / Rosales 1966 [1969²]) en lo que es una muestra más que revela la conexión personal y académica de ambos.

Fruto de esa relación amistosa son las doce cartas mínimas que editamos y estudiamos en este trabajo. Se conservan todas ellas en el Archivo Histórico Nacional dentro de la colección Luis Rosales ${ }^{7}$. Pueden agruparse en tres temáticas, que nos servirán también para separar en partes nuestro análisis:

cita (Alonso 1950 [1966]: 607, n. 9) un ejemplo usado por Rosales en su texto: «Algunas consideraciones sobre el lenguaje» (Escorial 1947).

4. Así lo declara a El País con ocasión de un homenaje que rindieron a Dámaso Alonso en la Universidad Internacional de Canarias (28-xii-1985).

5. Eulalia Galvarriato (1904-1997) tuvo cierta trayectoria literaria; fue finalista del primer premio Nadal con Cinco sombras, que quedó derrotada ante Nada de Laforet. Recientemente ha aparecido el texto teatral que escribió para su representación en el Liceo Serrano, que dirigía su hermana: Retablillo de Navidad y otros poemas (Ediciones Caballo Griego para la Poesía, 2004). En la correspondencia de Luis Rosales archivada como proveniente de Dámaso Alonso se guardan sendas tarjetas escritas por Galvarriato: una felicitación navideña de 1979 dedicada a "Maruja y Luis» y una tarjeta manuscrita, sin fecha, que acompaña al regalo de unas tazas (no se editan aquí). Galvarriato, además de organizar los papeles de Alonso, trabajó con él conjuntamente en publicaciones como Para la biografía de Góngora: documentos desconocidos (Madrid: Gredos, 1962).

6. El título era un guiño a la recopilación de romances de Pedro Arias Pérez (Lisboa, 1626) Primavera, $y$ flor de los mejores romances que han salido, aora nuevamente en esta corte. La antología fue publicada por Selecciones del Reader's Digest y en 1983 apareció de ella una tercera edición aumentada, en el Instituto Miguel de Cervantes/CSIC. La obra tuvo buena acogida como material divulgativo y escolar en su tiempo e incluso se incluyó en la Bibliografía de la literatura hispánica de Simón Díaz (vol. 1 referencia 1324). Rosales fue de 1965 a 1971 director del Gran diccionario enciclopédico ilustrado de Selecciones del Reader's Digest.

7. El Archivo Luis Rosales se compró a sus herederos en 1999. Está formado por 196 legajos y 4 carpetas, y se organiza temáticamente en nueve secciones. Las cartas que editamos tienen el código de referencia es. $28079 \mathrm{ahn} / 4.2 .42$ y se encuentran digitalizadas en la página http:// pares.mcu.es. El proyecto de digitalización de este fondo fue subvencionado por Caja Madrid a través de su entidad cultural "La Casa Encendida", y es de libre acceso (salvando algunos documentos personales o médicos que son de consulta restringida). Las cartas de respuesta de Luis Rosales están conservadas en la rae, en el fondo Luis Rosales y de momento (2015) están en proceso de catalogación. 
escritos más bien de trámite en torno a cuestiones editoriales (se describirán en $\$$ 3: proyectos encargados a Rosales, o participados con él; artículos de Alonso enviados a la revista dirigida por el poeta granadino o recomendaciones de publicación); escritos biográficos sobre experiencias personales (que abordaremos en $\$ 4$ ) y un escrito de naturaleza literaria (nos ocuparemos de él en $\$ 5)$.

3. Varias son las cartas que tienen que ver con cuestiones editoriales que Rosales y Alonso compartían, con distintos papeles respectivamente. Así, el documento I, el más antiguo de este grupo, revela el descontento de Alonso con Rosales por no haber recibido últimamente ejemplares de la revista Cuadernos Hispanoamericanos, que Rosales dirigió ${ }^{8}$, y solicitando dos ejemplares de un volumen concreto en que había aparecido un escrito suyo en torno a Pedro Salinas, en concreto su "Carta última a don Pedro Salinas» ${ }^{9}$ en que evoca los veintinueve años de amistad con el poeta ${ }^{10}$ :

(I) [Cuartilla mecanografiada con membrete del CSIC-Instituto Miguel de Cervantes de Filología Hispánica; sin datar; a partir de la firma se sigue escribiendo en forma manuscrita y se firma de nuevo]

Querido Rosales:

Haz el favor de enviarme lo antes que puedas un ejemplar del Cuadernos Hispanoamericanos en que va mi última carta a Pedro Salinas. Tengo compromiso de enviárselo a una monja norteamericana, discípula de Salinas, a quien se lo prometí.

Se lo pidió Huarte a Casamayor, de mi parte, pero se le ha debido olvidar a éste.

Muchas gracias.

Un abrazo

Dámaso

Serían de desear dos ejemplares; uno para la monja y otro para mí. A estas horas yo no he visto impreso mi trabajo (así da gusto). Ya te dije que sin aviso // previo, me

8. Rosales colaboró con la revista desde sus inicios en 1948 y la dirigió desde 1953 tras el breve paso de Pedro Laín Entralgo; dimitió en 1965 de ese cargo en protesta por la censura a un artículo sobre el asesinato de García Lorca, escrito por Ramón Garciasol. La revista, que aparece mencionada en este trabajo varias veces por ser un lugar de encuentro entre Rosales editor y Dámaso Alonso autor, «fue una prolongación más ambiciosa e independiente de Escorial (...) una revista clave de la posguerra» (Montetes-Mairal 2010: 41).

9. Este trabajo apareció en el ejemplar de Cuadernos Hispanoamericanos n. ${ }^{o} 31$ (julio de 1952, pp. 50-54), de modo que la carta a Rosales debió de ser escrita en torno a 1952-1953.

10. Se reproducen las cartas sin indicación de cambio de línea; para el cambio de página se emplea el signo de doble barra //; se transcriben en cursiva los subrayados de los originales; no se desarrollan las abreviaturas. Algunos de los documentos (por ejemplo, el vii) añaden una numeración a lápiz azul (o incluso alguna palabra: está), que es ajena al ahn y que apunta a algún ordenamiento interno salido de la casa de Rosales. No se transcriben los sobres, que se conservan en algunos casos. Dentro de la Colección Rosales del ahn, las cartas de Dámaso Alonso se encuentran numeradas internamente por fecha, situando al final aquellas sin datación. Dado que en este trabajo ofrecemos una propuesta de datación de todas ellas, no hemos respetado tal orden interno, y numeramos a partir de un eje temático y cronológico. 
dieron de baja (por lo visto) en la lista de suscriptores gratuitos. Tu $[s i c]$ me dijiste que lo remediarías; pero hasta ahora. Así me faltan los Cuadernos desde hace un año por lo menos (Tampoco me han pagado).

Claro que si no les interesa que yo lea y pueda propagar los Cuadernos tienen una idea bien pintoresca de la propaganda. En cambio los enviarán a cien sitios donde pasaran [sic] sin saludar a la cuesta del trapero o a sitio peor.

En fin, cosí va il mondo. Lo que me duele, es que tú no te acuerdes de mí.

Abrazo

Dámaso

Tengo para nuestros Cuadernos un buen artículo del Prof. Carilla de la Univ ${ }^{\mathrm{d}}$ de Tucumán sobre Amado Alonso en la Argentina. Creo que tiene interés el mostrar el trabajo heroico de un español en América.

Aparecen aquí mencionados los nombres de dos trabajadores del libro: Fernando Huarte Morton y Enrique Casamayor, ligados respectivamente a Dámaso Alonso y a Rosales. Huarte (1921-2011) trabajaba desde 1941 en la biblioteca de la Universidad de Madrid, y luego ejerció como secretario (1963-1975) y director (1975-1986) de la biblioteca de la Universidad Complutense $^{11}$. De su relación con Alonso da cuenta el apodo de Huartito con que Dámaso Alonso lo llamaba y la calificación que en la tesis doctoral ${ }^{12}$ de Huarte se hace a Alonso: "generoso maestro y protector mío». Ambos trabajaron juntos en la difusión en nuestro país de la obra de Werner Beinhauer Spanische Umgangsprache que Huarte tradujo (El español coloquial) y Dámaso Alonso prologó (1968) ${ }^{13}$. Por su parte, Casamayor fue secretario de Cuadernos Hispanoamericanos desde la época de Laín y había tenido contacto con otras revistas de creación (Díaz Hernández 2007: 214). Se menciona también en estas cartas al hispanista argentino Emilio Carilla (1914-1995) que Dámaso elogia en su escrito a Rosales y que finalmente colaboró como autor en dicha revista ${ }^{14}$ con el trabajo que encarecía Dámaso.

En el documento II, de 1956, Alonso encarga a Rosales un estudio sobre $\mathrm{La}$ escuela tradicional castellana en la poesía áurea, para salir en Gredos, editorial

11. Para los datos sobre Huarte tomo como fuente el Libro homenaje a Fernando Huarte Morton (1921-2011) publicado por la Complutense y disponible en http://eprints.ucm.es

12. «El ideario lingüístico de Miguel de Unamuno» (1949), publicado posteriormente por la Universidad de Salamanca.

13. Huarte es el coautor con A. Ramírez Ovelar de la Bibliografía de Dámaso Alonso publicada en Gredos (1998, Biblioteca Románica Hispánica).

14. El estudio de Carilla ("Amado Alonso, en la Argentina») apareció originalmente en Cuadernos Hispanoamericanos 51 (1954), 369-376 y luego se incluyó (ampliado) en su libro Estudios de literatura argentina (siglo XX), Tucumán: Facultad de Filosofía y Letras. En el trabajo se reconoce el peso de Dámaso Alonso en la continuidad de la investigación del otro Alonso: «Amado Alonso ha sido uno de los que más han hecho por difundir la estilística en el mundo hispánico. Hoy -sobre todo después de los últimos trabajos de Dámaso Alonso- quizá aparezcan algo alejados los de nuestro crítico; pero sería injusto no reconocer el valor ejemplar que tienen consideraciones teóricas y estudios de Amado Alonso» (p. 372). 
cuya colección «Biblioteca Románica Hispánica» dirigía, si bien este libro no llegó a salir.

II [Papel con membrete de la Editorial Gredos. Mecanografiado; manuscrito de la firma en adelante]

Madrid, 13 de diciembre de 1956

Sr. D. Luis Rosales

Altamirano 34

Madrid

Querido Luis Rosales:

Te ruego que contestes por escrito a la carta en la que te preguntaba si querrías hacer un tomo sobre La escuela tradicional castellana en la poesía del Siglo de Oro. Escríbeme a las señas de esta carta.

Un abrazo

Dámaso Alonso

Es que los editores necesitan llevar su registro.

$\mathrm{Al}$ igual que en el documento primero, la carta III muestra de nuevo a un Dámaso Alonso contrariado por un tema editorial, en concreto por lo que parece un acuerdo de derechos sobre el libro Primavera y flor de la literatura hispánica que escribió con Rosales y Galvarriato; no falta la alusión personal al final de la misiva:

III [Cuartilla manuscrita guardada en sobre matasellado en enero de 1963]

Hoy Martes

Q ${ }^{\text {do }}$ Luis:

Yo estoy aburrido con el asunto de Selecciones. No comprendo cómo estos señores pueden tomar con tanta tranquilidad que hace más de un año estén en descubierto conmigo. Yo deseo una solución amistosa, pero rápida. Tu $[s i c]$ ya conoces los terminos [sic] de mi propuesta.

Un abrazo

Dámaso

Ya sabrás que he estado con gripe.

Varias veces don Dámaso se dirige a Rosales solicitando un favor editorial para una tercera persona; así lo hacía en el documento I, y así lo vemos en los dos escritos que siguen (documentos IV y v). En el primero de ellos, Dámaso Alonso intercede ante Rosales en favor del profesor Ricardo Benavides Lillo (1929-2000), que ejerció en centros de educación superior de Chile y Estados Unidos y que estuvo de visita en España en los años setenta. Siendo Rosales (desde 1970) director del Instituto de Cultura Hispánica, Alonso se dirige a él y menciona la posibilidad de que pueda interceder Alfredo Sánchez Bella (1916-1999), director anterior de dicho Instituto (de 1946 a 1956) y ministro 
de Información y Turismo con Franco (1969-1973)15. En el documento v, ya en la década de los ochenta, Alonso le escribe a Rosales para que respalde editorialmente al escritor Julio Torres ${ }^{16}$ :

IV [Tarjeta manuscrita]

Sr. D. Luis Rosales, Altamirano 34

Querido Luis:

Te presento a Ricardo Benavides, estudiante chileno (licenciado en Letras en su país). Creo que Benavides es de lo más inteligente y preparado que ha pasado por aquí. Tiene ahora una dificultad // económica casi invencible. Y me pregunto si no habría posibilidad de una ayuda del Instituto de Cult ${ }^{a}$ Hispánica. Si no, Benavides se tendría que volver a Chile. Dime si crees que debo o puedo escribir o ver a Sanchez Bella. En fin, dime tu pronóstico.

Un abrazo de

Dámaso

v [Cuartilla manuscrita con membrete de la RAE]

30 de octubre 83

Querido Luis:

Mucho te agradecería que le publicaras algo en tu revista al excelente poeta y prosista Julio Torres, persona que creo que puede llegar a tener mucha fama. Es joven muy inteligente y con gran amplitud de temas para comentar Espero que me hagas caso y te envío un fuerte abrazo

Dámaso

En la última de las cartas de este grupo, no existen referencias a terceros ni a obra propia; se trata de un mero mensaje de trámite en que se agradece la remisión de un trabajo (posiblemente aparecido en prensa) de Rosales y lo emplaza a un encuentro próximo ${ }^{17}$.

15. Su relación con Rosales queda patente en la dedicatoria que este le hace del poema «Durar también es vivir» (Montetes-Mairal 2010: 349): «A Alfredo Sánchez Bella, dejando atrás el Puerto de las dos Castillas».

16. En el archivo personal de Rosales figuran varios originales mecanografiados de Torres (el poemario El año de antes y los textos en prosa El silencio responde si le llamas, Escena de estación con vagabundo y Lección de arquitectura) con la referencia AHN Diversos-Luis Rosales 92, N. 34 a N. 37. No consta que estos originales hayan sido publicados.

17. Es necesaria una nota sobre las sucesivas direcciones postales que aparecen en las cartas: Alberto Alcocer 23 es la casa en Chamartín en que residió Dámaso Alonso. La dirección de Altamirano 34 es la residencia de Rosales «desde 1944-1945 hasta finales de los años setenta, cuando se mudó al número 26 de la calle Vallehermoso, también en el barrio de Argüelles» (Montetes-Mairal 2010: 302 n.60); su otra residencia estaba en la sierra madrileńa, en Cercedilla, donde pasaba vacaciones y fines de semana y donde está enterrado. 
28 de septiembre, 1985

Avda. Alberto Alcocer, 25

28036-Madrid

Querido Luis:

Muchas gracias por tu estupendo artículo.

Tengo que irme enseguida de Madrid.

Dentro de unos diez días estaré de vuelta. Entonces querré visitarte. Y darte las gracias por tu felicidad hacia mí.

Un gran abrazo

Dámaso

Esta media docena de cartas de Alonso a Rosales, vertebradas en torno al núcleo temático del oficio de la escritura (propia o ajena) nos introduce en la vertiente más cotidiana del filólogo: la generosidad de sus recomendaciones, su contundencia al reclamar lo que entendía que le pertenecía y, de fondo a todos los escritos, su amistad y cercanía con el poeta nos permiten perfilar mejor su figura. En el obituario que Lapesa escribió sobre Dámaso Alonso, se describe el carácter del maestro con palabras que parecen condecir lo que emana de estas primeras seis cartas: «Era a la vez impulsivo y cauto, irritable y cordial, socarrón y niño. Jugaba a forjarse leyenda de egoísta y agarrado, pero se entregaba a los demás con abnegación y no ponía límites a su generosidad» (Lapesa 1998: 181).

4. Al segundo grupo pertenecen los tres documentos en que Dámaso escribe sobre cuestiones personales suyas o relativas a Rosales. Las dos misivas más antiguas de la colección que aquí se edita son precisamente de esa naturaleza; se trata de dos cartas en que Alonso lamenta la muerte de los padres de Rosales: Esperanza Camacho Corona (fallecida el 17 de enero de 1941) y Miguel Rosales Vallecillo (muerto solo cinco días después). A raíz del fallecimiento de su madre, Rosales empezó a escribir la elegía a ella que fue El contenido del corazón, editada finalmente en 1969, y varias veces declaró el poeta la huella que la orfandad imprimió a su obra.

VII [Folio manuscrito]

Chamartín, 2 de Enero 41

Mi querido Luis:

Nuestros deseos fueron inútiles y ha llegado lo irreparable. Yo sé que tú lo habrás recibido como un hombre, con esa mezcla de entrañable desgarro y de profunda, dulce piedad que es la hombría ante lo definitivo e inevitable. No te digo, pues, palabras de consuelo, sino que te sumerjas en ese vaho dentro: en el fondo de tu dolor estará tu consuelo. Desde lejos y desde fuera, yo te acompaño con todo mi cariño. Estaba ilusionado por las noticias optimistas de los días anteriores... Recibe, Luis, un abrazo muy fuerte de Dámaso 
vIII [Cuartilla manuscrita con membrete del CSIC-RFE]

Querido Luis:

Ahora mismo llega Muñoz con la noticia de tu nueva desgracia y nos quedamos todos aterrados. La vida suele escalonarnos estos golpes, pero contigo se ha ensañado con rara crueldad. ¡Pobre Luis! Es demasiado fuerte lo que te ocurre, y temo por tu salud. Cuídate y piensa que tienes por delante el deber de tu obra.

Te abraza fuertemente

Dámaso

Subrayamos en estas dos cartas que la transmisión del pésame de Alonso a Rosales se acompaña con palabras que son también una descripción de la propia poética que el maestro de la filología aplicó en su análisis de este poeta: el sentimiento de piedad de Rosales (en el fondo de tu dolor estará tu consuelo le dice al granadino). En la segunda carta, Alonso esgrime un imperativo poético: piensa que tienes por delante el deber de tu obra.

Un sentido más cordialmente festivo tienen las dos tarjetas postales que editamos bajo los números Ix y x. En la primera, firmada por Dámaso Alonso y [Antonio Rodríguez-] Mońino, se mandan recuerdos a Rosales desde Portugal en escala a Argentina ${ }^{18}$. Por su parte, el documento x, como el anterior, también guarda testimonio autógrafo de don Dámaso (y de su mujer) y de otro interlocutor epistolar. Se trata de una postal remitida desde Valencia el 13 de octubre de 1959 en la que figura la letra de un tal "Rafael". Debe de tratarse de Rafael Ferreres ${ }^{19}$ (1914-1981), profesor que tuvo cierta relación con Dámaso Alonso en su etapa valenciana (de 1933 a 1939 Alonso fue catedrático en Valencia) y al que dedicó alguna publicación (Ferreres 1958); Ferreres escribió una reseńa del libro sobre el Conde de Villamediana escrito por Rosales. Dámaso Alonso estuvo en Valencia en esa fecha para formar parte del jurado del certamen literario $V$ Centenario de la muerte de Ausias March en colaboración con Gerardo Diego, Carles Riba (luego sustituido por Salvador Espriu), José M. ${ }^{a}$ Castellet, Arturo Zabala y Joan Fuster ${ }^{20}$. La celebración de este premio, otorgado a José Agustín Goytisolo por Claridad, ocasiona el viaje y la escritura en recuerdo al amigo.

18. Del viaje de Dámaso Alonso y Rodríguez-Moñino a Buenos Aires quedó otra constancia en la dedicatoria de "El manuscrito del Fausto» (1943) con texto «Para mi querido hermanillo Dámaso, de Amado. Buenos Aires 1945» (Polo 2007: 438).

19. Se descarta por completo que sea Rafael Lapesa, no es la letra la de este filólogo ni estaba en Valencia en esa fecha. Existió una cordial amistad entre Rosales y Lapesa, testimoniada en misivas que se guardan en el Fondo Luis Rosales del ahn; son media docena de tarjetas enviadas por Lapesa sin otra información que saludos o felicitaciones. Remito a mi trabajo sobre las cartas de Rafael Lapesa a Dámaso Alonso conservadas en la RAE para más datos acerca de esta terna de amigos.

20. La convocatoria del premio puede verse en la edición facsímil de Sicania (1958-1959), año II, n. ${ }^{\circ}$ 7, Valencia, enero de 1959 editada en 2001 por la Universitat de València. De la deliberación de ese jurado y de una anécdota protagonizada por Dámaso Alonso informa Castellet (2009). 
IX [Tarjeta postal de Elvas, matasellada en marzo de 1945 dirigida a L.R. a la revista Escorial]

En nuestra ruta a Buenos Aires, nos acordamos mucho de ti, y te enviamos un fuerte abrazo.

Dámaso y Moñino

$\mathrm{x}$ [Tarjeta postal con imagen nocturna de Valencia, matasellada el 13 de octubre de 1959]

Querido Luis:

Un recuerdo desde Valencia con deseo de que ya estés bueno.

Saludos cordiales a Maruja

Dámaso Eulalia

[con otra letra figura el texto que sigue:]

Me ha dicho Dámaso que te ha gustado la nota que hice a tu C. de V. y me alegra saberlo.

Carińosos abrazos para ti y carińosos saludos a tu mujer de

Rafael.

Aún más jugoso es el último texto de este grupo, que enhebra en la narración detalles sobre el mundo intelectual y personal de Alonso, quebrado, como el de tantos españoles, por la separación forzosa de aquellos amigos que marcharon al exilio. La carta XI es la más extensa de toda la colección aquí editada y es abundante en nombres y noticias de los exiliados en torno a Boston. Dámaso Alonso estuvo en New Haven invitado para dictar algunos cursos en la Universidad de Yale en $1948^{21}$ y allí o desde allí volvió a ver a muchos españoles instalados antes de la guerra o salidos después, por la sangría del exilio forzoso. La carta es sin duda la más interesante de toda la colección de epístolas:

XI [Cuartillas manuscritas sin sobre ni fecha]

Yale Station 979

New Haven, Conn

Qdo Luis:

Pero hombre; hasta cuándo te vas a estar cayendo de la bici? Ponte bueno enseguida. Ayer, no, anteayer, estuve en Boston comiendo con Paquito G. Lorca y con Amado y con Claudio el chico de Jorge, ya ves qué 4 comensales, y nos reunimos por pura casualidad.

El otro día comí aquí con don Amós Salvador, ¿̨te acuerdas que fue Ministro con Azaña? tambien [sic] eramos [sic] // un grupo de españoles curioso: un Dr. Durán Reynals, catalán, gran especialista en investigación sobre el cancer [sic] (tiene aquí fama), el Dr. Angulo (tío de mi Marisol Carrasco, qué chica más estupenda, Luis, si tu $[s i c]$ ya no fueras un vejestorio), el Dr. Ochoa, que era ayudante de la cátedra de

21. Además del viaje de 1948, hay otras estancias de Dámaso Alonso en Estados Unidos: en 1953 fue profesor de la John Hopkins de Baltimore. 
Negrín (valía mucho más que él) y le han hecho catedratico [sic] de la Univ de Nueva York y Amós y yo. ¡Cuánto hablamos de España! Todos buena gente, inteligentes. ¡Qué pena! // Me ha escrito Eduardo Vicente desde N. York: que está muy aburrido, que no entiende la lengua.

Estuve viendo a Clavería y a Emilio Lorenzo en Filadelfia. Dormí en casa de Clavería. Estuve dos días con don Pedro en Baltimore. Dos días hablando sin cesar. Claro que te hemos nombrado muchas veces (y a Leopoldo, aunque no se lo merece).

Pocos días después de volver yo a New Haven dió a luz Solita un niño (Carlos). Ya es // don Pedro abuelo. ¡Qué barbaridad!

¿Qué te has roto?

¿Qué tal va el Góngora? Aprieta, por si lo tuvieras que hacer solo.

No se está mal por aquí, despues [sic] de todo, aunque no se come más que bazofia.

Adios grande hombre $[s i c]$

Pronto bueno, pronto.

Cuéntame todo lo que te has roto y cómo.

un abrazo

Dámaso

No te va eso de la bici. No te va ni gota.

Se puede subrayar el papel de Dámaso Alonso (Alonso 1952) en esa carta como puente entre los excluidos (que él trata) y los incluidos (Rosales, al que escribe o Leopoldo [Panero] al que menciona con desafecto). Se menciona en la carta a un grupo de intelectuales de lo que se ha llamado el exilio republicano en Estados Unidos ${ }^{22}$. Si bien hubo profesores universitarios y escritores españoles exiliados por toda América, en las universidades de Estados Unidos se concentraron varios de ellos, en gran parte gracias a la ayuda que prestó Federico de Onís, antiguo miembro del Centro de Estudios Históricos y persona de muchas responsabilidades en el ámbito de la hispanística norteamericana (Niño 2007): Amado Alonso en Harvard, Américo Castro en Princeton, Pedro Salinas en Johns Hopkins, Jorge Guillén en Wellesley College o Luis Cernuda (brevemente) en Mountain Holyoke College. En la carta de Alonso se nombra, pues, a más de una docena de espańoles instalados en Estados Unidos a los que visita o de los que tiene noticias. La carta apenas da noticias, es más un censo de nombres de quien, suponemos, noticiar con detalle a Rosales a la vuelta a España.

Todos los que se citan son intelectuales (profesores, literatos, artistas), pero también hay un político: el arquitecto Amós Salvador Carreras (1879-1963), ministro de la Gobernación con Azaña unos breves meses de 1936, miembro de Acción Repúblicana y de Izquierda Republicana, que estuvo exiliado en América hasta 1950. El resto son amigos o conocidos de amigos. Entre los

22. Al respecto de este grupo de exiliados puede verse el libro monográfico de Faber / Martínez Carazo (2010), quienes afirman: «los exiliados llegaron en un momento propicio ya que, gracias en parte al empuje del panamericanismo por parte del gobierno de Roosevelt, había gran demanda de profesores de espańol». 
amigos, se han de subrayar los nombres de Amado Alonso y Pedro Salinas. Amado Alonso estaba ya instalado en Harvard, después de cerrar su estancia en Argentina (1927-1946) acosado por el peronismo. Tenía con Dámaso Alonso una amistad profunda, como dan cuenta los varios escritos que se dedicaron mutuamente los dos Alonsos. El artículo de Dámaso Alonso «Amado Alonso ante la muerte» (Alonso 1952 b) y la necrológica que le escribió en la Revista de Filología Española lo constata así: «los mejores títulos son la obra que deja y los discípulos que formó. Y fuera ya de lo científico, la limpieza de su alma hecha para el bien y para la generosidad. Y la pena que nos queda en el corazón a los que fuimos sus amigos».

Amado Alonso es mencionado a vuela pluma; en cambio, se demora algo más la escritura al tratar de Pedro Salinas, don Pedro para Alonso. Salinas se había establecido en la Johns Hopkins de Baltimore (con un paréntesis de 1941 a 1946 en que estuvo en Puerto Rico) y su hija, Soledad Salinas (19202007) acababa de dar a luz a su hijo Carlos (Marichal Salinas) el 10 de marzo de 1948. Ello permite datar el año de esta carta sin fecha. Cuando Dámaso Alonso lo visita, el poeta está viviendo «su etapa más dura del exilio americano» (Morgado 2010: 47), en la que escribe las piezas de Todo más claro y otros poemas (1949), donde «expresa las angustias de un hombre que vive en un país ajeno y profundamente contradictorio». Y de este viaje de Alonso da cuenta, como en un espejo, el propio epistolario de Pedro Salinas: en una de sus cartas a Jorge Guillén (11 de marzo de 1948) (Salinas /Guillén 1992: 438) escribe Salinas de la visita que Dámaso Alonso le hizo a Baltimore:

Estuvo Dámaso la semana pasada. Pasamos grandes ratos juntos. Está mejor que nunca, muy bien de aspecto, y más Dámaso que jamás lo estuvo, serio y apasionado, y burlón y cazurro, según vayan las cosas, y en todo momento simpatiquísimo y admirable. ¡Qué alegría no sentir disminuidos en nada los motivos de la amistad, y su vigencia! [...] De España, habló con su franqueza e independencia de criterio de siempre, y con su fatal impronta de hombre que vive allí. El resultado es que tras explicar, o explicarse, su vida allí, uno siente la imposibilidad absoluta, para uno, de vivir en España. Y al mismo tiempo se respeta, y casi diría que se aprueba, su resuelta decisión de volverse allí, enseguida. Esto no le importa nada, en absoluto, ni el país, ni las personas, ni la cultura.

La relación de Alonso con Jorge Guillén y sobre todo con Pedro Salinas es de profundo afecto y admiración mutuas ${ }^{23}$; así, Guillén escribe a Salinas el 5 de marzo de 1944 (Salinas / Guillén 1992: 323):

23. El epistolario de Salinas a Guillén incluye abundantes referencias a Dámaso, relativas tanto a las lecturas que hace de sus escritos como de los encuentros que tiene con él en Estados Unidos. En 1951 refiere una visita de Alonso a Nueva York: «Dámaso, magnífico. [...] Me da la impresión de estar en el momento más pleno y feliz de su producción de crítico. El crítico mejor que ha tenido la poesía española desde... ¿̇desde cuándo? Por supuesto en este siglo no hay quien le llegue» (Salinas / Guillén 1992: 560). Curiosamente, la última de las cartas que dirige Salinas a Guillén antes de morir termina con estas palabras: «Amado mejor. Viene bastante. dámaso no me ha escrito nada" [mayúsculas en original]. 
Dejaré para otro día otras mil menudencias. Pero no quiero aplazar el decirte la noticia más importante para mí -de carácter literario- en estos últimos meses: Dámaso ha vuelto a la poesía, y ha publicado una serie de poemas -15- Oscura noticia, que son estupendos. [...] Los poemas de Dámaso me dieron una inmensa alegría. ¿No los has visto ya? Lo tienen todo: pasión, ferocidad, delicadeza, dominio -y una maestría absoluta, y voz tradicional y personal, muy español todo y muy Dámaso.

Alonso también ve allí a «el chico de Jorge», hijo de Guillén, que es el veinteañero entonces Claudio Guillén (1924-2007). También se menciona al hermano menor de Federico, Francisco García Lorca (1902-1976), al que llama Dámaso Alonso «Paquito», instalado en Nueva York que trabajaba entonces como profesor en Queens College ${ }^{24}$. Alude también a Emilio Lorenzo (1918-2002) que ese curso (1947/1948) estaba de profesor en la Universidad de Pennsylvania después de haber pasado por Múnich y Bonn y que luego trabajaría con Dámaso Alonso en la traducción del libro de Walther von Wartburg de 1943 Problemas y métodos de la lingüistica publicado en 1951 por el CSIC. De la relación amistosa entre ambos dejaría otra huella el propio Dámaso al prologar el famoso libro de Emilio Lorenzo El español de hoy, lengua en ebullición (Madrid: Gredos, 1966). Se menciona también a Carlos Clavería (1909-1974), que tras ser lector de varias universidades europeas se había establecido en 1946 en Estados Unidos, como profesor de Lenguas Románicas en la Universidad de Pennsylvania hasta 1955 (con un lapso del curso 1947/1948 en que ejerció como profesor visitante en Harvard).

No falta el humor en esta carta, como cuando Alonso encomia a su Marisol Carrasco y se ríe de Rosales (aún soltero, se casó con la gallega María Fouz -Maruja- en abril de 1950) diciendo que es un vejestorio para ella. Se refiere ahí don Dámaso a Soledad Carrasco Urgoiti (1922-2007), que tenía veintiséis años cuando estaba escribiendo Alonso. La nieta de Nicolás M. ${ }^{a}$ de Urgoiti, fundador del diario El Sol se había formado en la órbita del ILE dentro del Instituto-Escuela y se había trasladado a Nueva York en 1946 aprovechando

24. El propio Rosales se entrevistó con él en 1949, en Nueva York, en una escala que hizo Rosales en su viaje a Cuba (Díaz de Alda 2012 describe cómo ese encuentro «fue organizado por Carlos Clavería»). Como es sabido, las relaciones entre la familia Rosales y los García Lorca en Granada fueron muy intensas en el verano de 1936, pues en la casa granadina de los Rosales se alojó Lorca para resguardarse de la guerra recién iniciada. La atribución de responsabilidad a la familia Rosales en la detención de Federico persiguió a Luis Rosales durante toda su vida y ha sido detalladamente desmontada en trabajos históricos aparecidos desde los ańos ochenta. Los propios coetáneos de ambos poetas no creyeron nunca en una conexión: Salinas escribe a Jorge Guillén en 1950 (Salinas / Guillén 1992: 519): «En Cuba parece que Rosales-Panero tuvieron acogida tumultuosa, con escándalo; Lazo me escribió si yo sabía algo de la responsabilidad que le imputan a Rosales en la muerte de Federico. Yo le he dicho que es pura malicia, otra porquería de la pasión política». Salinas tenía en alta estima a Rosales como poeta, y en marzo de 1936, ya establecido en Estados Unidos pero aún sin explotar el conflicto militar en Espańa, dice a Guillén en torno al segundo Cántico: «En cuanto a crítica futura y posible, estoy animando a Luis Rosales, el cual de suyo está muy bien dispuesto. Ese grupo de muchachos (Rosales, Vivanco, los Panero, los Bleiberg) me parecen lo más serio e interesante de la gente joven, cuidadosos de alejarse de todo energumenismo y trabajadores» (Salinas/Guillén 1992: 170). 
que se había instalado allí su tía M. ${ }^{a}$ Luisa Urgoiti. Carrasco, que vivió en el mismo edificio que la familia García Lorca desde 1949, estaba en esos años empezando una carrera de investigación que hubo de ser muy fructífera ${ }^{25}$ y muy probablemente fue el enlace en aquel viaje de Dámaso Alonso con el mundo de la medicina. La carta da cuenta también de cómo conoce a trasterrados españoles integrados en la docencia universitaria norteamericana dentro de departamentos de ciencias. Menciona a Francisco Durán Reynals (1899-1958), médico español establecido en los Estados Unidos desde 1926 y profesor en Yale hasta su fallecimiento (Peiró Rando 1963). El tío de Marisol Carrasco, Guillermo Angulo Pastor, profesor de Pediatría en la cátedra de Enfermedades de la Infancia dirigida por Enrique Suñer, se había exiliado a México y luego a Estados Unidos (Otero 2006: 104) y parece ser quien le presenta a Alonso a un joven Severo Ochoa (1905-1993) a quien el maestro se refiere como "el Dr. Ochoa», que en efecto, como dice Alonso en su carta había sido desde 1931 ayudante de Negrín en su cátedra y que, tras pasar por Alemania y el Reino Unido se había afincado en 1940 en Estados Unidos, concretamente desde 1945 en la Universidad de Nueva York.

Por último, también es aludido como contacto postal el pintor Eduardo Vicente (1909-1968), quien ese mismo año había ilustrado con algunos dibujos el libro de Dámaso Alonso Oscura noticia (1948), hermano del también pintor Esteban Vicente. Eduardo Vicente, director del Museo Ambulante de Misiones Pedagógicas, amigo de Cossío y de D’Ors, fue muy conocido en el ámbito pictórico e intelectual de la posguerra y había sido becado en 1948 con Saenz de Oiza para viajar a Nueva York por la Real Academia de Bellas Artes de San Fernando (Calvo Serraller 1991: 836).

Dos revelaciones hay en esa carta. La principal, esa exclamación de «todos buena gente, inteligentes, iqué pena!» que resume la postura ante el exilio de Dámaso Alonso; la segunda, más anecdótica, la ingratitud que atribuye a Leopoldo, que es sin duda el poeta Leopoldo Panero, de carácter controvertido pero muy relacionado personalmente con Luis Rosales y Dámaso Alonso. Rosales había dedicado parte de los poemas de La casa encendida a su hermano, Juan Panero, fallecido prematuramente en 1937 y también dedicó algún poema al propio Leopoldo Panero, quien fue secretario de una de las secciones del Instituto de Cultura Hispánica que dirigió Rosales. Por su parte, el poema «Mujer con alcuza», posiblemente el más conocido de cuantos escribió Alonso, está dedicado a Panero y en 1962 le dedicó a su muerte el poema "Última noche de amistad». A su vez, Panero también dedicó escritos a Alonso (Panero 1958), lo que verifica la continuidad de relación entre estos tres poetas antes y después de la fecha de la carta.

25. Carrasco leyó en la Universidad de Columbia su tesis y fue profesora de la Universidad de la ciudad de Nueva York. Especialista en literatura áurea, es conocida su monografía de 1956 El moro de Granada en la literatura (Del siglo XV al XX) Madrid: Publicaciones de la Revista de Occidente. 
5. Uno solo de los documentos localizados de Dámaso Alonso dentro del fondo Luis Rosales del AHN tiene naturaleza literaria, pero es de soporte y (aparentemente) ambiente muy informal. Se trata de una tarjeta del Hotel Ritz con el menú impreso de una cena ${ }^{26}$, sobre ella se escriben algunas referencias espaciales de Madrid, y en el reverso una declaración primopersonal de Dámaso Alonso acerca de la poesía espańola contemporánea:

XII [Tarjetón de un menú dado en el Ritz, sábado 20 de mayo de 1944]

Cafe del Prado; Calle del Prado.

La Saeta

Bar de la Plaza del Rey. Aqui recogió la cartera Leopoldo. Casa de Salvador Libertad esquina Gravina Situacion probable cartera.

[siguen palabras y números sueltos, ilegibles]

// Creo que la posible poesía española arranca de "Sobre los ángeles", "Espadas como labios" y la "Destrucción o el Amor".

Madrid 20 de Mayo 1944

Dámaso Alonso

Ah! Y «Cántico», y «Cántico»

D.A.

Este manifiesto festivo, que llegaría a las manos de Rosales posiblemente por compartir con él la velada en que Dámaso lo escribe, ensalza a Rafael Alberti (Sobre los ángeles, 1929), Vicente Aleixandre (Espadas como labios, 1932; La destrucción o el amor, 1935) y Jorge Guillén (Cántico, 1928 la primera serie). El canon que se elige es llamativo, por cuanto no figuran en él referencias que fueron muy repetidas por Dámaso Alonso al enjuiciar la poesía del siglo XX (como Pedro Salinas), y porque se limita a dos poetas, con una apostilla sobre Guillén. No puede darse al escrito una solemnidad o una relevancia que no merece, pero no deja der un documento interesante sobre la presencia de la poesía como objeto de conversación en ese grupo de amigos castigado por las ausencias del exilio y la guerra.

6. En el largo poema «Cuando a escuchar el alma me retiro» que se incluye como cuarta parte de La casa encendida, Rosales incluye una evocación de sus amigos (vv. 960-961) en que actualiza el refrán clásico sobre Sancho con el nombre de Dámaso: «luego vendrán Pedro y Primitivo, con Leopoldo, Dionisio, y Alfonso, y el buen callar que llaman Dámaso».

Ese buen callar parece que emana también de estas cartas de Dámaso Alonso, cortas, sucintas y, hasta la más larga y llena de noticias, muy contenida en calificativos. No estamos, claro es, ante cartas que se dirigen a personas distanciadas en el espacio o en la intimidad. Cabe de estas esperar mayor morosidad en la narración de episodios profesionales o personales propios,

26. No existen referencias en prensa ni en el archivo del citado hotel sobre esa cena o su posible carácter conmemorativo, público o privado. 
mayor tendencia, tal vez, al desvío hacia el manifiesto o la declaración de principios. Son estas misivas las huellas de un trato cercano, su exiguo número compensado por el trato cercano y constante en persona o por la llamada rutinaria.

Subrayemos, aun así, la paradójica circunstancia que aloja la modesta colección que aquí hemos editado. La carta más reveladora de la opinión de Dámaso Alonso y su sentir sobre la Espańa del exilio es la escrita más lejos de Madrid (XI), en tanto que es la nota XII, casual huella de una sobremesa nocturna y festiva, la que -si es tomada con toda literalidad- revela de forma más descarnada (por sucinta) el credo literario de don Dámaso sobre la poesía española contemporánea. Escrita una en la lejanía del amigo, otra rubricada junto a él; una nacida de la sombra de tristeza de la España instalada en Norteamérica, la otra firmada cinco años después de la guerra en el marco chispeante de una velada en el Ritz. En Dámaso Alonso se observan esas contradicciones que padecieron muchos de los intelectuales de la posguerra. Que un conjunto epistolar mínimo como este la refleje tan fielmente es uno de los guiños que nos depara la investigación filológica de textos.

\section{Bibliografía}

Alonso Dámaso, 1944 [1962], «Luis Rosales: la lírica barroca y los desengaños de Imperio", Escorial XIII, 39, 1944, 275-283, recogido en D. Alonso, Del siglo de oro a este Siglo de siglas. Notas y artículos a través de 350 años de letras españolas, 1962, p. 78-89.

-1950 [1966], «Función imaginativa del lenguaje», Poesía española. Ensayo de métodos y límites estilísticos. Garcilaso, Fray Luis de León, San Juan de la Cruz, Góngora, Lope de Vega, Quevedo. Madrid: Gredos, 1950 [1966], p. 604-610.

- 1952 a, "Amado Alonso (1896-1952)», (Necrológica), Revista de Filología Española xxxvi, 1952, pp. 206-208.

- 1952 b, «Amado Alonso ante la muerte», Ínsula, 78, 15 de junio de 1952, pp. 1-2.

- 1962 a, "Dos cartas", Del Siglo de oro a este siglo de siglas. Notas y artículos a través de 350 años de letras españolas. Madrid: Gredos, 1962, p. 75-77.

- 1962 b, «España en las cartas de Pedro Salinas», Insula vii, 74, recogido en Del Siglo de oro a este siglo de siglas. Notas y artículos a través de 350 años de letras españolas. Madrid: Gredos, [1952] 1962, p. 154-162.

- 1964, «Contestación al discurso de Luis Rosales en la Real Academia Española, 19 de abril de 1964», recogido en Obras completas. Estudios y ensayos sobre literatura. Tercera parte, ensayos sobre literatura comparada, 1964 [1975].

Alonso Dámaso, Eulalia Galvarriato, Luis Rosales, 1966 [1969], Primavera y flor de la literatura hispánica, (4. vols.), Madrid: Selecciones del Reader's Digest, 1966 [1969]. $534 p p+610 p p+520 p p+824 p p$. 
Calvo Serraller Francisco, 1991, Enciclopedia del arte español del siglo XX. 1. Artistas. Madrid: Mondadori, 1991.

Castellet José M. ${ }^{a}$, 2009, Seductors, il.lustrats $i$ visionaris. Sis personatges en temps adversos, Barcelona: Edicions 62, 2009.

Díaz de Alda Heikkilä M. ${ }^{a}$ Carmen, 2012, «Rosales y García Lorca: Desde los Versos del combatiente a Nueva York después de muerto», en Luis Rosales, ed. M. ${ }^{a}$ Carmen Díaz de Alda Heikkilä, Espéculo. Revista de Estudios Literarios 49, 2012. Disponible en http://www.ucm.es/info/especulo/lrosales/indice_art.html

Díaz Hernández Onésimo, 2007, «Las revistas culturales en la España de la posguerra (1939-1951): una aproximación», Cuadernos del Instituto Antonio de Nebrija 10, 2007, p. 201-224.

Faber Sebastiaan, Cristina Martínez-Carazo (eds.), 2010, Contra el olvido. El exilio español en Estados Unidos, Alcalá de Henares (Madrid): Instituto Universitario de Investigación en Estudios Norteamericanos Benjamín Franklin, 2010, 241 pp.

Ferreres Rafael, 1958, «Dámaso Alonso: catedrático en Valencia», Ínsula XIII, 1958, p. 138-139, 15.

Hernández Mario, 1993, "Dámaso Alonso y Jorge Guillén: fragmentos de una correspondencia (1926-1981)», Revista de Occidente 4. ${ }^{a}$ época, 144, 1993, p. 1942.

Homenaje universitario a Dámaso Alonso. Reunido por los estudiantes de Filología románica, curso 1968-1969. Madrid: Gredos, 1970.

Lapesa Rafael, 1998, Generaciones y semblanzas de claros varones y gentiles damas que ilustraron la filología hispánica de nuestro siglo. Madrid: Real Academia de la Historia, 1998.

Libro homenaje a Fernando Huarte Morton (1921-2011), E-Prints Complutense, disponible en http://eprints.ucm.es

Morgado Nuria, 2010, «Pedro Salinas en Nueva York: Avisos del poeta exiliado desde la ciudad metafísica», en Faber Sebastiaan, Martínez Carazo (eds.), Contra el olvido. El exilio español en Estados Unidos, Alcalá de Henares (Madrid), 2010, p. 47-60.

Niño Antonio, 2007, «El exilio intelectual republicano en los Estados Unidos», Cuadernos de Historia Contemporánea, vol. extraordinario, 2007, p. 229-244.

Otero Carvajal Luis Enrique (dir.), 2006, La destrucción de la ciencia en España. Depuración universitaria en el franquismo, Madrid: Editorial Complutense, 2006, $365 \mathrm{pp}$.

- 2006, «La depuración de la Universidad de Madrid», en La destrucción de la ciencia en España. Depuración universitaria en el franquismo, Luis Enrique Otero Carvajal (dir.), Madrid: Editorial Complutense, 2006, p. 73-148.

Panero Leopoldo, 1958, "Dámaso Alonso en su montaña», Papeles de Son Armadans, III, XI, XXXII-XXXIII, 1958, p. 364-369. 
Peiró Rando Enric, 1963, «El Dr. Francisco Durán Reynals, médico español», Actas del I Congreso Español de Historia de la Medicina, Madrid-Toledo: Sociedad Española de Historia de la Medicina, 1963, p. 457-460.

Polo José, 2007, «Correspondencia científica (1927-1952) Dámaso Alonso / Amado Alonso (5)», Cauce. Revista de Filología y su Didáctica 30, 2007, p. 357-383.

- 2011, «Materiales de archivo de Dámaso Alonso (serie menor: 10) [Carta a Blanca García-Valdecasas sobre La puerta de los sueños]», Analecta Malacitana 34,1, 2011, p. 213-231.

Pons Rodríguez Lola, 2016, «Un epistolario para la Filología: las cartas de Rafael Lapesa a Dámaso Alonso», en Araceli López Serena, Antonio Narbona, Santiago del Rey Quesada (coords.), El español a través del tiempo: estudios ofrecidos a Rafael Cano Aguilar, Vol. 2, Sevilla: Servicio de Publicaciones de la Universidad de Sevilla, 2016, pp. 1177-1195.

Rivero Machina Antonio, 2013, «Luis Rosales y Luis Felipe Vivanco: una lectura heroica de imperio y desengaños», Castilla. Estudios de literatura 4, 2013, p. 157 176.

Rosales Luis, 1947, «Algunas consideraciones sobre el lenguaje», Escorial, Tomo XVIII, Cuaderno 55, 1947.

- 1979, Rimas y La casa encendida, Prólogos de Dámaso Alonso y Julián Marías, Madrid: Espasa-Calpe, 1979.

-2010, La casa encendida. Rimas. El contenido del corazón, Edición de Noemí MontetesMairal y Laburta, Madrid: Cátedra Letras Hispánicas, nº 667, 2010.

Ruiz-Gálvez Priego Estrella (dir.), 2013, Dámaso Alonso-Marcel Bataillon: un epistolario en dos tiempos. Madrid: Fundación Universitaria Española, 2013.

Salinas Pedro / Jorge Guillén, 1992, Correspondencia (1923-1951), Edición, introducción y notas de Andrés Soria Olmedo. Barcelona: Tusquets Editores, 1992. 
